\title{
Cancer screenee cohort study of the National Cancer Center in South Korea
}

\author{
Jeongseon Kim \\ Molecular Epidemiology Branch, Division of Cancer Epidemiology and Prevention, Research Institute, National Cancer Center, Goyang, Korea
}

\begin{abstract}
The Cancer Screenee Cohort Study was first established in 2002 by the National Cancer Center in South Korea to investigate all possible risk factors related to cancers and to expand biological specimen banking for the development of effective methodologies for cancer detection, diagnosis, and prevention. As of July in 2014, total 41,105 participants were enrolled in this cohort. Data were collected via questionnaire, clinical examination, cancer screening, and biological specimen testing including blood, urine, and exfoliated cervical cells. The highest incidence was found to be thyroid cancer, according to a nested case-control study that was linked to the National Cancer Registry information as of December 31, 2011. Case-control, cross-sectional, and cohort studies have been published using these data since 2009. Diet and nutrition was the most published topic, followed by genetics, hepatitis B virus and liver cancer screening, methodologies, physical activity, obesity, metabolic syndrome, smoking and alcohol consumption, and blood type. Evidence from the Cancer Screenee Cohort Study is highly anticipated to reduce the burden of cancer in the Korean population and aid in the detection, diagnosis, and prevention of cancer.
\end{abstract}

KEY WORDS: National Cancer Center, Cancer, Cohort, Korea

\section{INTRODUCTION}

A cohort study is one type of observational research design performed over a specific follow-up period in which individuals with an incident disease of interest are compared with those who do not develop the disease. In South Korea, the Korean Multi-Center Cancer Cohort study (KMCC) was established in four geographically-defined urban and rural regions in 1993 and included adults in the general population-based over 35 [1]. This study was designed to investigate the relationship between exposures to specific factors (e.g., lifestyle) and the risk of can-

\section{Correspondence: Jeongseon Kim}

Molecular Epidemiology Branch, Division of Cancer Epidemiology and Prevention, Research Institute, National Cancer Center, 323 Ilsan-ro, Ilsandong-gu, Goyang 410-769, Korea

Tel: +82-31-920-2570, Fax: +82-31-920-2579, E-mail: jskim@ncc.re.kr

Received: Jun 12, 2014, Accepted: Aug 6, 2014, Published: Aug 6, 2014

This article is available from: http://e-epih.org/

(C) 2014, Korean Society of Epidemiology

(C) This is an open-access article distributed under the terms of the Creative Commons Attribution License (http://creativecommons.org/licenses/by/3.0/), which permits unrestricted use, distribution, and reproduction in any medium, provided the original work is properly cited. cers in the Korean population. Another population-based prospective cohort study, the Korean Genome and Epidemiology Study (KoGES), was initiated by the Korea Centers for Disease Prevention and Control in 2001 [2]. The KoGES was designed to determine genetic and environmental risk factors of major chronic diseases such as metabolic syndrome, diabetes, obesity, hypertension, cardiovascular disease, cancer, and others. To collect this large-scale epidemiological and clinical data as well as biospecimens, a national infrastructure for biomedical research was established. In South Korea, three major cohort studies have been established through KoGES: 1) a community-based cohort (in Ansan and Ansung cities, $\mathrm{n}=10,038$ ) and a rural community-based cohort ( $\mathrm{n}=28,000), 2)$ a health-examinee cohort $(n=174,000), 3)$ a special cohort consisting of twins and families $(n=3,300)$, Korean emigrants $(n=3,600)$, immigrants after marriage $(n=7,500)$, and members of the Asian Collaborative Cohort $(n=4,000)$. It is expected that the findings of these studies will significantly decrease the burden of chronic diseases and increase the quality of life for Koreans [2].

Other developed countries such as the US, Japan, and Europe initiated large cohort studies throughout the last few decades to investigate the associations between risk factors and cancers. 
For example, the Japan Public Health Center-based prospective study on cancer and cardiovascular diseases was based in 11 public health centers and included a study population of more than 140,000 participants who had been followed from 1990 (cohort I) and 1993 (cohort II) [3]. This study was designed to provide evidence-based data for the prevention and control of cancer and cardiovascular diseases. In the US, the Nurse's Health Study started in 1976, particularly focused on cancers and other chronic conditions [4]. In Europe, the European Prospective Investigation into Cancer and Nutrition was developed as a multi-center prospective cohort study throughout 23 centers in
10 European countries and included more than 500,000 participants [5]. This European study was designed to investigate the association between nutrition and cancer using dietary questionnaires collecting data on usual diet intake. In China, the ShanghaiWomen's Health Study was established between 1996 and 2000 and recruited approximately 75,000 adult Chinese women from urban communities to investigate the major incidence of cancers and the influence of anthropometric risk factors such as smoking, alcohol intake, and others [6]. Similar to the women's study, the Shanghai Men's Health Study recruited a total of 61,500 adult Chinese men between 2001 and 2006 to

Table 1. Distribution of selected demographic factors in this cohort

\begin{tabular}{|c|c|c|c|}
\hline Variables & Male $(n=20,680)$ & Female $(n=20,425)$ & Total $(n=41,105)$ \\
\hline \multicolumn{4}{|l|}{ Age groups (yr) } \\
\hline $30-39$ & 2,786 (13.5) & $2,566(12.6)$ & $5,352(13.0)$ \\
\hline $40-49$ & $7,575(36.6)$ & 7,764 (38.0) & 15,339 (37.3) \\
\hline $50-59$ & $6,603(31.9)$ & 6,885 (33.7) & $13,488(32.8)$ \\
\hline $60-70$ & $3,716(18.0)$ & $3,210(15.7)$ & 6,926 (16.9) \\
\hline \multicolumn{4}{|l|}{ Marital status } \\
\hline Never married & $627(3.0)$ & $663(3.2)$ & 1,290 (3.1) \\
\hline Currently married & $18,039(87.2)$ & $16,045(78.6)$ & 34,084 (82.9) \\
\hline Widowed & $166(0.8)$ & $1,025(5.0)$ & $1,191(2.9)$ \\
\hline Divorced/separated & $372(1.8)$ & $792(3.9)$ & $1,164(2.8)$ \\
\hline Unknown & $1,476(7.1)$ & $1,900(9.3)$ & $3,376(8.2)$ \\
\hline \multicolumn{4}{|l|}{ Education level } \\
\hline Middle school or less & $2,079(10.1)$ & $3,470(17.0)$ & $5,549(13.5)$ \\
\hline High school & $5,574(27.0)$ & $7,666(37.6)$ & $13,240(32.3)$ \\
\hline College or more & $11,257(54.5)$ & $6,929(33.9)$ & $18,186(44.2)$ \\
\hline Unknown & $1,770(8.6)$ & $2,360(11.6)$ & $4,130(10.0)$ \\
\hline \multicolumn{4}{|c|}{ Household income (1,000 Korean won/mo) } \\
\hline$<200$ & $2,256(10.9)$ & $3,182(15.6)$ & $5,438(13.2)$ \\
\hline $200-400$ & $5,783(28.0)$ & $5,271(25.8)$ & 11,054 (26.9) \\
\hline$\geq 400$ & $9,778(47.3)$ & $7,413(36.3)$ & $17,191(41.8)$ \\
\hline Unknown & $2,863(13.8)$ & $4,559(22.3)$ & $7,422(18.1)$ \\
\hline \multicolumn{4}{|l|}{ Occupation } \\
\hline Professional, administration & $6,677(32.3)$ & $1,870(9.2)$ & $8,547(20.8)$ \\
\hline Office worker & $3,474(16.8)$ & $1,416(6.9)$ & $4,890(11.9)$ \\
\hline Sales, services & $3,792(18.3)$ & $2,601(12.7)$ & $6,393(15.6)$ \\
\hline Agriculture, manual labor & $3,255(15.7)$ & $1,005(4.9)$ & $4,260(10.4)$ \\
\hline Housewife & $15(0.1)$ & $10,858(53.2)$ & $10,873(26.5)$ \\
\hline Unemployed, retired & $1,670(8.1)$ & $540(2.6)$ & $2,210(5.4)$ \\
\hline Unknown & $1,797(8.7)$ & $2,135(10.5)$ & $3,932(9.6)$ \\
\hline \multicolumn{4}{|l|}{ Smoking status } \\
\hline Never smoker & $3,825(18.5)$ & $16,376(80.2)$ & $20,201(49.1)$ \\
\hline Ex-smoker & $7,883(38.1)$ & $664(3.3)$ & $8,547(20.8)$ \\
\hline Current smoker & $7,945(38.4)$ & $895(4.4)$ & $8,840(21.5)$ \\
\hline Unknown & $1,027(5.0)$ & $2,490(12.2)$ & $3,517(8.6)$ \\
\hline \multicolumn{4}{|l|}{ Alcohol consumption } \\
\hline Never drinker & 2,432 (11.8) & $9,808(48.0)$ & $12,240(29.8)$ \\
\hline Ex-drinker & 1,308 (6.3) & $825(4.0)$ & 2,133 (5.2) \\
\hline Current drinker & $15,711(76.0)$ & 7,736 (37.9) & $23,447(57.0)$ \\
\hline Unknown & $1,229(5.9)$ & $2,056(10.1)$ & $3,285(8.0)$ \\
\hline \multicolumn{4}{|l|}{ Family history of cancer } \\
\hline No & 6,567 (31.8) & 6,829 (33.4) & $13,396(32.6)$ \\
\hline Yes & $13,177(63.7)$ & $12,175(59.6)$ & $25,352(61.7)$ \\
\hline Missing & $936(4.5)$ & $1,421(7.0)$ & $2,357(5.7)$ \\
\hline
\end{tabular}

Values are presented as number (\%). 
investigate the influence of dietary and lifestyle factors on cancers and other chronic diseases [7].

Adapted after careful review of these previously implemented cohort studies, the Cancer Screenee Cohort Study was established in 2002 by the Center for Cancer Prevention and Detection at the National Cancer Center (NCC) in South Korea. The purpose of this study is to investigate possible risk factors related to cancers and to expand the banking of biological specimens for the development of effective methodologies for cancer detection, diagnosis, and prevention in the Korean population. In last decade, several influential cohort studies have been established and developed with the help of Korean government. In particular, the NCC collects some of the most representative data on cancer epidemiology, and it is highly anticipated that these data will help reduce the burden of cancer in the Korean population. Herein, this paper is to introduce the establishment and achievements of the Cancer Screenee Cohort Study at both national and international levels since 2002.

\section{STUDY PARTICIPANTS}

From August 2002 till July 2014, 41,105 participants aged between 30 and 70 years were enrolled in this cohort study. Collected demographic data included the participants' age, gender, marital status, education level, household income, job, smoking habits, alcohol consumption, and family history of cancer (Table 1). Participants who agreed to enroll in this cohort study were interviewed by trained personnel completed a health examination. Data were collected via questionnaire (e.g., past medical history), clinical tests (e.g., chest X-ray), physical examinations (e.g., blood pressure), cancer screenings (e.g., Pap smear), blood tests (e.g., cholesterol), urine tests (e.g., routine urinalysis), and other biological specimens (e.g., buffy coat) at the Center for Cancer Prevention and Detection at the NCC (Table 2). Trained personnel attempted to collect any missing information after the baseline collection via telephone. Until now, 44,234 participants have provided informed consent, 41,105 completed lifestyle questionnaire. Plasma were collected in 38,375 participants (vial $n=159,816$ ), buffy coat in 38,356 (vial $n=74,385$ ), red blood cell count in 38,358 (vial $n=76,337$ ), serum in 37,760 (vial $\mathrm{n}=141,553$ ), whole blood samples in 9,097 (vial $\mathrm{n}=27,073$ ). In addition, DNA was extracted in 19,209 participants, spot urine in 18,228, and uterine cervical exfoliated cells in 6,447 women.

\section{ETHICAL CONSIDERATIONS}

The institutional review board of NCC approved this study in August 2002. All participants provided informed consent, were informed of their right to withdraw from the study at any time without penalty, and were informed that the purpose of this study is to detect, diagnose, and prevent cancer in South Korea.

Table 3. The number of incident cancer cases ${ }^{1}$

\begin{tabular}{lrrr}
\hline Subsites & Men & Women & Total \\
\hline Thyroid & 184 & 323 & 507 \\
Stomach & 128 & 61 & 189 \\
Colorectum & 103 & 52 & 155 \\
Lung & 83 & 40 & 123 \\
Breast & 1 & 106 & 107 \\
Prostate & 99 & - & 99 \\
Liver & 58 & 9 & 67 \\
Kidney & 25 & 3 & 28 \\
Bladder & 25 & 2 & 27 \\
Gallbladder & 12 & 5 & 17 \\
Pancreas & 14 & 1 & 15 \\
All cancers & 824 & 674 & 1,498 \\
\hline
\end{tabular}

${ }^{1}$ Data were linked to the Korean National Cancer Incidence Database from the Korea Central Cancer Registry as of December 31, 2011 [8].

Table 2. Description of health examination tests performed on cohort participants

\begin{tabular}{|c|c|}
\hline Questionnaires/tests & Measurements \\
\hline Questionnaire & $\begin{array}{l}\text { Demographics, past medical history, family history of disease, occupation, medication use, cigarette smoking including } \\
\text { environmental tobacco smoking, alcohol intake, food frequency questionnaire (food items/groups) or 3-day dietary } \\
\text { records, female reproductive history }\end{array}$ \\
\hline Clinical tests & Electrocardiogram, pulmonary function test, chest X-ray, body composition analysis (impedance), bone density (DEXA) \\
\hline Physical measurements & Blood pressure, pulse, height, weight, waist circumference, visual acuity test \\
\hline Cancer screenings & $\begin{array}{l}\text { Esophagogastroduodenoscopy, mammography, cytology of cervix uteri (Pap smear), stool occult blood/colono-sigmoido- } \\
\text { scopy/liver USG + aFP }\end{array}$ \\
\hline Blood tests & $\begin{array}{l}\text { Fasting plasma glucose, total cholesterol, high density lipoprotein cholesterol, low density lipoprotein cholesterol } \\
\text { (direct measure), triglyceride, total protein, albumin, gamma-glutamyl transferase, aspartate aminotransferase, } \\
\text { alanine amino transferase, creatinine, calcium, uric acid, complete blood cell count with differential count }\end{array}$ \\
\hline Urine tests & Routine urinalysis \\
\hline Biological specimens & $\begin{array}{l}\text { Plasma, buffy coat, red blood cell, serum, whole blood, extracted DNA, random spot urine, uterine cervical exfoliated cells } \\
\text { (women) }\end{array}$ \\
\hline
\end{tabular}




\section{MEASUREMENT OF INCIDENT CANCER CASES}

By matching resident registration numbers with participants, the incidence of cancer cases in the cohort was confirmed by linking with the Korea National Cancer Incidence Database of the Korea Central Cancer Registry [9]. The incidence of all cancer cases $(n=1,498$, male $=824$, female $=674)$ as of December 31, 2011, was calculated by employing a nested case-control study. Table 3 shows the results of these calculations. Thyroid cancer had the highest incidence $(n=507)$ in males $(n=184)$ and females $(n=323)$, followed by stomach $(n=189,128$ males, 61 females), colorectum ( $\mathrm{n}=155,103$ males, 52 females), lung $(\mathrm{n}=123,83$ males, 40 females), breast $(\mathrm{n}=107,1$ male, 106 females), prostate ( $n=99,99$ males), liver ( $n=67,58$ males, 9 females), kidney ( $\mathrm{n}=28,25$ males, 3 females), bladder ( $\mathrm{n}=27,25$ males, 2 females), gallbladder ( $\mathrm{n}=17,12$ males, 5 females), and pancreas cancer ( $n=15,14$ males, 1 female).

\section{KEY FINDINGS AND PUBLICATIONS}

Since 2009, the results of this study have been published in scientific journals. Published topics include diet and nutrition (14 publications) [10-23], genetic analyses (5 publications) [24$28]$, hepatitis B virus and liver cancer screenings (3 publications) [29-31], methodologies (3 publications) [32-34], physical activity (2 publications) [35,36], obesity (2 publications) [37,38], metabolic syndrome (1 publication) [39], smoking and alcohol consumption ( 1 publication) [40], and blood type ( 1 publication) [41]. Among these published studies, most employed a case-control study designs (17 publications) followed by crosssectional (13 publications) and cohort study designs (2 publications) (Table 4). Published data using a cross-sectional design primarily used data from self-questionnaires to investigate the

Table 4. List of published papers using data from the Cancer Screenee Cohort Study

\begin{tabular}{lccc}
\hline & \multicolumn{3}{c}{ Study type [reference] } \\
\cline { 2 - 4 } & $\begin{array}{c}\text { Cross- } \\
\text { sectional }\end{array}$ & $\begin{array}{c}\text { Case- } \\
\text { control }\end{array}$ & Cohort \\
\hline Diet and nutrition & {$[10-16]$} & {$[17-23]$} & - \\
Genetic analyses & - & {$[24-28]$} & - \\
Hepatitis B virus and liver cancer & {$[29-31]$} & - & - \\
$\quad$ screenings & & & - \\
Methodologies & {$[32]$} & {$[33,34]$} & - \\
Physical activity & {$[35,36]$} & - & - \\
Obesity & - & - & {$[37,38]$} \\
Metabolic syndrome & - & {$[39]$} & - \\
Smoking and alcohol consumption & - & {$[40]$} & - \\
Blood type & - & {$[41]$} & -
\end{tabular}

association between risk factors such as diet, physical activity, smoking, and alcohol consumption and chronic diseases (e.g., obesity, osteoporosis, metabolic syndrome, and colorectal adenomas). In addition, liver cancer incidence was associated with socioeconomic and lifestyle factors. Moreover, a nested casecontrol study on thyroid cancer is currently in progress and research on stomach, lung, and prostate cancer is expected to be completed for the next three to four years. However, cancers with a low incidence rate require active long-term.

Data from this cohort study will help determine risk factors of specific cancers in the Korean population. The findings of this study are also expected to be used for the development of a scientific model to determine the influence of interactions between genetic and environmental factors, and provide evidencebased preventive medicine at an individual level. Moreover, the findings of this study will aid in the design and evaluation of policies on a national level and in the exchange of scientific knowledge and manpower to coordinated future national and international studies.

\section{ACKNOWLEDGEMENTS}

Jeonghee Lee and Wook Jin Choi, researchers in Molecular Epidemiology Branch at National Cancer Center, aided in the drafting of this manuscript. This study was supported by a grant from the National Cancer Center, Republic of Korea (no. 1210140).

\section{CONFLICT OF INTEREST}

The author has no conflicts of interest to declare for this study.

\section{REFERENCES}

1. Yoo KY, Shin HR, Chang SH, Lee KS, Park SK, Kang D, et al. Korean Multi-center Cancer Cohort Study including a Biological Materials Bank (KMCC-I). Asian Pac J Cancer Prev 2002;3:85-92.

2. Korean Society of Epidemiology. 2013 Fall Academic Conference Proceedings: Korean Genome and Epidemiology Study (KoGES); 2013 Dec 5; Busan. Busan: Korean Society of Epidemiology; 2013, p. 93-104 (Korean).

3. Tsugane S, Sobue T. Baseline survey of JPHC study--design and participation rate. Japan Public Health Center-based Prospective Study on Cancer and Cardiovascular Diseases. J Epidemiol 2001;11:S24S29.

4. International Agency for Research on Cancer (IARC). Cancer epidemiology: principles and methods. Lyon: IARC; 1999, p. 165-187.

5. Riboli E, Hunt KJ, Slimani N, Ferrari P, Norat T, Fahey M, et al. European Prospective Investigation into Cancer and Nutrition (EPIC): study populations and data collection. Public Health Nutr 2002;5:11131124.

6. Zheng W, Chow WH, Yang G, Jin F, Rothman N, Blair A, et al. The 
Shanghai Women's Health Study: rationale, study design, and baseline characteristics. Am J Epidemiol 2005;162:1123-1131.

7. National Cancer Institute. Cohort Consortium. Shanghai Men's Health Study: cohort study of cancer - inhibitory factors in men; 2013 [cited 2014 May 26]. Available from: http://epi.grants.cancer.gov/Consortia/members/smhs.html.

8. Korea Central Cancer Registry. Annual report of cancer statistics in Korea in 2011; 2013 [cited 2014 May 26]. Available from http://ncc. re.kr/manage/manage03_033_view.jsp?bbsnum=295\&hSelSearch= \&hTxtKeyword=\&current_page $=1 \& c d=$ null (Korean).

9. Korea Central Cancer Registry. Annual report of cancer statistics in Korea in 2010; 2012 [cited 2014 May 26]. Available from http://ncc. re.kr/manage/manage03_033_view.jsp?bbsnum=250\&hSelSearch= $\&$ hTxtKeyword $=\&$ current page $=1 \&$ cd $=$ null (Korean).

10. Shin A, Lim SY, Sung J, Shin HR, Kim J. Dietary intake, eating habits, and metabolic syndrome in Korean men. J Am Diet Assoc 2009; 109:633-640.

11. Kim J, Lee JS, Shin A, Kang MH, Shin DS, Chung HR, et al. Sociodemographic and lifestyle factors are associated with the use of dietary supplements in a Korean population. J Epidemiol 2010;20: 197-203.

12. Shin A, Lim S, Sung J, Myung S, Kim J. Dietary habit and bone mineral density in Korean postmenopausal women. Osteoporos Int 2010;21:947-955.

13. Cho ER, Shin A, Lim SY, Kim J. Dietary patterns and their associations with health behaviours in Korea. Public Health Nutr 2011;14: 356-364.

14. Cho YA, Shin A, Kim J. Dietary patterns are associated with body mass index in a Korean population. J Am Diet Assoc 2011;111:11821186.

15. Cho YA, Kim J, Cho ER, Shin A. Dietary patterns and the prevalence of metabolic syndrome in Korean women. Nutr Metab Cardiovasc Dis 2011;21:893-900.

16. Youn S, Woo HD, Cho YA, Shin A, Chang N, Kim J. Association between dietary carbohydrate, glycemic index, glycemic load, and the prevalence of obesity in Korean men and women. Nutr Res 2012; 32:153-159.

17. Kim J, Lim SY, Shin A, Sung MK, Ro J, Kang HS, et al. Fatty fish and fish omega-3 fatty acid intakes decrease the breast cancer risk: a case-control study. BMC Cancer 2009;9:216.

18. Yu H, Hwang JY, Ro J, Kim J, Chang N. Vegetables, but not pickled vegetables, are negatively associated with the risk of breast cancer. Nutr Cancer 2010;62:443-453.

19. Shin A, Kim J, Lim SY, Kim G, Sung MK, Lee ES, et al. Dietary mushroom intake and the risk of breast cancer based on hormone receptor status. Nutr Cancer 2010;62:476-483.

20. Cho YA, Kim J, Park KS, Lim SY, Shin A, Sung MK, et al. Effect of dietary soy intake on breast cancer risk according to menopause and hormone receptor status. Eur J Clin Nutr 2010;64:924-932.

21. Cho YA, Kim J, Shin A, Park KS, Ro J. Dietary patterns and breast cancer risk in Korean women. Nutr Cancer 2010;62:1161-1169.

22. Kim KZ, Shin A, Kim J, Park JW, Park SC, Choi HS, et al. Association between CASR polymorphisms, calcium intake, and colorectal cancer risk. PLoS One 2013;8:e59628.

23. Woo HD, Park KS, Shin A, Ro J, Kim J. Glycemic index and glycemic load dietary patterns and the associated risk of breast cancer: a case-control study. Asian Pac J Cancer Prev 2013;14:5193-5198.

24. Yoon KA, Park S, Hwangbo B, Shin HD, Cheong HS, Shin HR, et al. Genetic polymorphisms in the Rb-binding zinc finger gene RIZ and the risk of lung cancer. Carcinogenesis 2007;28:1971-1977.

25. Miki D, Kubo M, Takahashi A, Yoon KA, Kim J, Lee GK, et al. Variation in TP63 is associated with lung adenocarcinoma susceptibility in Japanese and Korean populations. Nat Genet 2010;42:893-896.

26. Yoon KA, Park JH, Han J, Park S, Lee GK, Han JY, et al. A genomewide association study reveals susceptibility variants for non-small cell lung cancer in the Korean population. Hum Mol Genet 2010;19: 4948-4954.

27. Joung JY, Lee YS, Park S, Yoon H, Lee SJ, Park WS, et al. Haplotype analysis of prostate stem cell antigen and association with prostate cancer risk. J Urol 2011;185:2112-2118.

28. Joung JY, Park S, Yoon H, Lee SJ, Park WS, Seo HK, et al. Association of common variations of $8 \mathrm{q} 24$ with the risk of prostate cancer in Koreans and a review of the Asian population. BJU Int 2012;110: E318-E325.

29. Shin A, Cho ER, Kim J, Sung J, Park KW, Lim MK, et al. Factors associated with awareness of infection status among chronic hepatitis B and C carriers in Korea. Cancer Epidemiol Biomarkers Prev 2009; 18:1894-1898.

30. Yun EH, Lim MK, Oh JK, Park JH, Shin A, Sung J, et al. Combined effect of socioeconomic status, viral hepatitis, and lifestyles on hepatocelluar carcinoma risk in Korea. Br J Cancer 2010;103:741-746.

31. Cho ER, Shin A, Choi KS, Lee HY, Kim J. Factors associated with use of ultrasonography screening for hepatocellular carcinoma among hepatitis B or C carriers. Cancer Epidemiol 2010;34:713-716.

32. Lee DH, Shin A, Kim J, Yoo KY, Sung J. Validity of self-reported height and weight in a Korean population. J Epidemiol 2011;21:3036.

33. Park B, Ma SH, Shin A, Chang MC, Choi JY, Kim S, et al. Korean risk assessment model for breast cancer risk prediction. PLoS One 2013;8:e76736.

34. Lee JH, Kim KH, Park JW, Chang HJ, Kim BC, Kim SY, et al. Lowmass-ion discriminant equation: a new concept for colorectal cancer screening. Int J Cancer 2014; 134:1844-1853.

35. Cho ER, Shin A, Kim J, Jee SH, Sung J. Leisure-time physical activity is associated with a reduced risk for metabolic syndrome. Ann Epidemiol 2009;19:784-792.

36. Kim KZ, Shin A, Lee J, Myung SK, Kim J. The beneficial effect of leisure-time physical activity on bone mineral density in pre- and postmenopausal women. Calcif Tissue Int 2012;91:178-185.

37. Nam SY, Choi IJ, Nam BH, Park KW, Kim CG. Obesity and weight gain as risk factors for erosive oesophagitis in men. Aliment Pharmacol Ther 2009;29:1042-1052.

38. Boffetta P, Hazelton WD, Chen Y, Sinha R, Inoue M, Gao YT, et al. Body mass, tobacco smoking, alcohol drinking and risk of cancer of the small intestine--a pooled analysis of over 500,000 subjects in the Asia Cohort Consortium. Ann Oncol 2012;23:1894-1898.

39. Kim BC, Shin A, Hong CW, Sohn DK, Han KS, Ryu KH, et al. Association of colorectal adenoma with components of metabolic syndrome. Cancer Causes Control 2012;23:727-735.

40. Shin A, Hong CW, Sohn DK, Chang Kim B, Han KS, Chang HJ, et al. Associations of cigarette smoking and alcohol consumption with advanced or multiple colorectal adenoma risks: a colonoscopy-based case-control study in Korea. Am J Epidemiol 2011;174:552-562.

41. Woo SM, Joo J, Lee WJ, Park SJ, Han SS, Kim TH, et al. Risk of pancreatic cancer in relation to $\mathrm{ABO}$ blood group and hepatitis $\mathrm{C}$ virus infection in Korea: a case-control study. J Korean Med Sci 2013; 28:247-251. 